OPEN ACCESS

Edited by:

Arieh Zaritsky,

Ben-Gurion University of the Negev,

Israel

Reviewed by:

Patrick Hallenbeck

University of Montreal, Canada

Lydia Robert,

Institut National de la Recherche

Agronomique, France

*Correspondence:

Beronda L. Montgomery,

Department of Energy-Plant Research

Laboratory, Michigan State University,

612 Wilson Road, Room 106, East

Lansing, MI 48824-1312, USA

montg133@msu.edu

Specialty section:

This article was submitted to Microbial Physiology and Metabolism, a section of the journal

Frontiers in Microbiology

Received: 07 March 2015 Accepted: 09 May 2015

Published: 26 May 2015

Citation:

Montgomery BL (2015) Light-dependent governance of cell shape dimensions in cyanobacteria.

Front. Microbiol. 6:514.

doi: 10.3389/fmicb.2015.00514

\section{Light-dependent governance of cell shape dimensions in cyanobacteria}

\author{
Beronda L. Montgomery ${ }^{1,2 *}$ \\ 'Department of Energy-Plant Research Laboratory, Michigan State University, East Lansing, MI, USA, ${ }^{2}$ Department \\ of Biochemistry and Molecular Biology, Michigan State University, East Lansing, MI, USA
}

The regulation of cellular dimension is important for the function and survival of cells. Cellular dimensions, such as size and shape, are regulated throughout the life cycle of bacteria and can be adapted in response to environmental changes to fine-tune cellular fitness. Cell size and shape are generally coordinated with cell growth and division. Cytoskeletal regulation of cell shape and cell wall biosynthesis and/or deposition occurs in a range of organisms. Photosynthetic organisms, such as cyanobacteria, particularly exhibit light-dependent regulation of morphogenes and generation of reactive oxygen species and other signals that can impact cellular dimensions. Environmental signals initiate adjustments of cellular dimensions, which may be vitally important for optimizing resource acquisition and utilization or for coupling the cellular dimensions with the regulation of subcellular organization to maintain optimal metabolism. Although the involvement of cytoskeletal components in the regulation of cell shape is widely accepted, the signaling factors that regulate cytoskeletal and other distinct components involved in cell shape control, particularly in response to changes in external light cues, remain to be fully elucidated. In this review, factors impacting the inter-coordination of growth and division, the relationship between the regulation of cellular dimensions and central carbon metabolism, and consideration of the effects of specific environment signals, primarily light, on cell dimensions in cyanobacteria will be discussed. Current knowledge about the molecular bases of the light-dependent regulation of cellular dimensions and cell shape in cyanobacteria will be highlighted.

Keywords: cell division, cellular morphology, cyanobacteria, morphogenes, photomorphogenesis

\section{Introduction}

Cyanobacteria and other photosynthetic organisms, which have limited mobility in their environment, are exquisitely sensitive to changes in environmental conditions. Cues that impact growth, development, and metabolism of these organisms include light, nutrients, and other factors such as inter-organismal interactions, including predation. As photosynthetic organisms depend upon light for driving energy-producing photosynthesis, these organisms are finely tuned to perceive changes in the photoenvironment. Properties of light that impact organismal form and function include light quality or prevalent wavelengths (visible and ultraviolet or UV), light intensity, daily cycles of dark/light cues, and interactions of light with other factors such as the availability of nutrients.

Light can positively promote organismal development; however, in excess it can also induce lightassociated damage or phototoxicity, particularly in photosynthetic organisms (reviewed by Busch and Montgomery, 2015). Thus, changes in growth, development, or metabolism in response to light can be photomorphogenic or photoprotective in nature. Morphological changes can be linked to 
the optimization of the utilization of resources to support growth and development in bacterial generally (Young, 2006, 2007). A role for light in regulating cell shape or morphology occurs across many organisms, including prokaryotes (Bennett and Bogorad, 1973; Bordowitz and Montgomery, 2008; Singh and Montgomery, 2011) and eukaryotes (Daniel and Rusch, 1962; Desnos et al., 1996; Gendreau et al., 1997; Marwan, 2001; Nishihama et al., 2015). The specific mechanisms by which light impacts morphology have not been vastly studied; however, in some cases photomorphogenesis is linked to the regulation of cytoskeleton proteins (Putzer et al., 1984; Poetsch et al., 1989; Kadota and Wada, 1992; Dyachok et al., 2011; Lindeboom et al., 2013; Singh and Montgomery, 2014). Notably, the regulation of cell shape is correlated with cytoskeletal components and/or function across a range of organisms (Smith, 2003; Mathur, 2004; Cabeen and Jacobs-Wagner, 2005, 2007; Stewart, 2005; Carballido-López, 2006; Osborn and Rothfield, 2007; Terenna et al., 2008; Margolin, 2009; Ueki and Nishii, 2009).

Changes in cyanobacterial shape specifically can be directly linked to growth and/or development-light-dependent changes in vegetative cell shape (Bennett and Bogorad, 1973) or cellular differentiation, e.g., nitrogen fixation-associated development of heterocysts (Kumar et al., 2010), spore-like akinete formation for surviving harsh or stressful environments (Rippka et al., 1979; Flores and Herrero, 2010; Kaplan-Levy et al., 2010), or motility-associated hormogonium induction (Rippka et al., 1979; Meeks and Elhai, 2002; Wong and Meeks, 2002; Adams and Duggan, 2008). These developmentally induced changes in cellular morphology can be tuned by environmental cues, which include light and/or nutrient availability (Singh and Montgomery, 2011; Vadia and Levin, 2015). Stress-induced changes in cellular morphology also occur frequently in bacterial cells. UV, temperature, salt, osmotic, and biotic stresses have known impacts on the morphology of cyanobacterial cells (reviewed Singh and Montgomery, 2011). Knowledge about the mechanisms by which developmental- or stress-related cues result in morphological changes has only recently begun to emerge. Such mechanisms include light-and photoreceptor-dependent regulation of morphogene expression and cytoskeletal protein accumulation (Pattanaik and Montgomery, 2010; Singh and Montgomery, 2014), regulation of reactive oxygen species (ROS) levels that are associated with morphological determination (Singh and Montgomery, 2012; Singh et al., 2013) and light-driven changes in second messenger homeostasis that have the potential to modulate cell shape or dimensions (Neunuebel and Golden, 2008; Agostoni and Montgomery, 2014). Also noted are nutrient-associated, cell division-related cues (Goclaw-Binder et al., 2012; Osanai et al., 2013), among others.

\section{Light-Modulated Regulators Drive Adaptation of Cellular Morphology in Cyanobacteria}

Light quality- or wavelength-dependent changes in physiology and development occur in some cyanobacteria (Bennett and Bogorad, 1973; Bordowitz and Montgomery, 2008). The wellstudied, freshwater filamentous cyanobacerium Fremyella

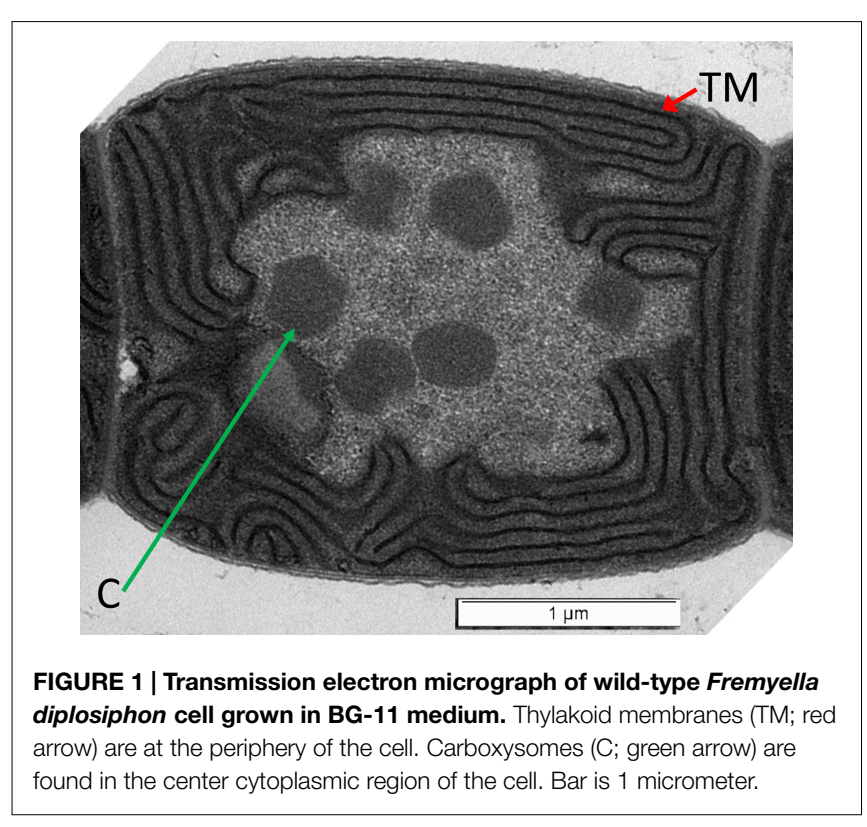

diplosiphon exhibits an acclimatory phenomenon, which is historically known as complementary chromatic adaptation or CCA, during which the photosynthetic pigment content is tuned to the external environment (Bennett and Bogorad, 1973; Tandeau de Marsac, 1991). The organism accumulates red-colored, green wavelength-absorbing pigment phycoerythrin $(\mathrm{PE})$ in green-enriched environments, and conversely blue-greencolored, red wavelength-absorbing pigment phycocyanin (PC) in red-enriched environments (Gutu and Kehoe, 2012). The PE and PC pigments are contained in peripheral light-harvesting complexes called phycobilisomes (PBS). The PBS antennae are associated with the thylakoid membranes generally found at the periphery of cyanobacterial cells (Figure 1). As the availability of red vs. green wavelengths vary significantly at difference depths in a water column, CCA-dependent tuning of photosynthetic pigmentation is linked to environmental adaptation and tuning of photosynthetic efficiency in natural contexts (Campbell, 1996; Postius et al., 2001). This process is regulated by a soluble, lightabsorbing photoreceptor known as RcaE in F. diplosiphon (Kehoe and Grossman, 1996). As a part of CCA, there are noted changes in cellular morphology, in addition to pigmentation. Spherical cells and shorter filaments are characteristic of growth under red light (RL), whereas rectangular cells and long filaments are associated with growth under green light (GL; Bennett and Bogorad, 1973; Bordowitz and Montgomery, 2008). RcaE is the regulator for cell shape and filament morphology changes, in addition to its previously mentioned role in fine-tuning photosynthetic pigment levels in F. diplosiphon (Bordowitz and Montgomery, 2008). RcaE mutant cells exhibit a rounded cell shape independent of the external light conditions, in contrast to the light-regulated switch between spherical- and rod-shaped cells observed for wild-type (Bennett and Bogorad, 1973; Bordowitz and Montgomery, 2008).

Apart from RcaE which is linked to the regulation of pigmentation and morphology in F. diplosiphon, another regulator cpeR has also been linked to the regulation of both pigmentation and morphology in this organism (Pattanaik et al., 2011b). CpeR 
induces synthesis of the photosynthetic pigment PE in GL (Cobley et al., 2002; Seib and Kehoe, 2002; Alvey et al., 2003). However, it was also shown that a $\Delta c p e R$ mutant in F. diplosiphon exhibits an altered cellular morphology compared to wild-type cells (Pattanaik et al., 2011b). Thus, the CpeR regulator, which appears to serve as a transcriptional activator for PE genes (Cobley et al., 2002), also likely controls genes important for photoregulation of cellular morphology. Notably, many other pigment mutants isolated in F. diplosiphon impact pigmentation of cells with no measurable impact on cellular morphology (Whitaker et al., 2009, 2011; Bordowitz et al., 2010; Pattanaik et al., 2011a,b).

Light intensity has been shown to impact cellular morphology in cyanobacteria (Bittencourt-Oliveira et al., 2012; Pattanaik et al., 2012; Walters et al., 2013). Cylindrospermopsis raciborskii exhibits trichome elongation under reduced light intensity (BittencourtOliveira et al., 2012). In F. diplosiphon, lower intensity light results in elongated cells, whereas light of increased intensity results in cells which are more spherical and with reduced length (Pattanaik et al., 2012; Walters et al., 2013). In natural environmental contexts, elongated $F$. diplosiphon cells are prevalent in low light intensities, whereas spherical cells exist in higher intensity regions of the water column (Montgomery, 2008). Thus, it was proposed that cells may regulate cellular morphology in natural contexts under different light intensities to control cellular volume and associated capacity for total photosynthetic membrane content that is correlated with regulation of cellular photosynthetic capacity (Montgomery, 2008; Pattanaik et al., 2012; Walters et al., 2013). As related photoreceptors serve as potent light quality and intensity sensors (e.g., Reed et al., 1994; Rausenberger et al., 2010), it is proposed that RcaE serves as a mediator of light intensitydependent regulation of morphology in F. diplosiphon.

Visible and UV light exposure can result in trichome spiral compression in Arthrospira platensis (Wu et al., 2005; Ma and Gao, 2009). The mechanism of this morphological regulation has been implicated as a periplasmic protein of undetermined function (Ma and Gao, 2009). Spiral compression in this organism may serve a role in self-shading that can protect cells against damaging UV exposure (Wu et al., 2005). Thus, the smaller, compressed state under UV has been correlated with reduced surface area that has been hypothesized to serve as a photoprotective state associated with the maintenance of photosynthetic capacity (Singh and Montgomery, 2011). Relatedly, trichome breakage or filament fragmentation under UV light also occurs in A. platensis and other cyanobacteria (Gao et al., 2007; Ma and Gao, 2010; Rastogi et al., 2010, 2014). Similar to trichome compression, these responses may be associated with reduced surface area potentially exposed to UV and a potential reduction in UV-associated damage.

\section{Light-Dependent Regulation of Morphogenes is One Mechanism for Regulating Cellular Morphology in Cyanobacteria}

Although distinct links between environmental signals and modulation of cellular morphology are clear in cyanobacteria (Singh and Montgomery, 2011), knowledge about the mechanisms by which these changes are mediated is limited. TonB is important for regulating GL-dependent cellular morphology in F. diplosiphon (Pattanaik and Montgomery, 2010). Although its exact biochemical function has not been elucidated, the protein has sequence similarity to both iron-associated TonB proteins and a glycine-rich region related to domains in proteins involved in cellular elongation (Sachetto-Martins et al., 2000; Pattanaik and Montgomery, 2010). However, the GL-associated disruption in photoregulation of morphology in a $\Delta$ tonB mutant in $F$. diplosiphon was shown to be independent of responses to iron limitation (Pattanaik and Montgomery, 2010). This observation, thus, suggests a more direct role for TonB in modulating cell shape in response to GL in this organism.

Recently, photoregulation of morphogenes has emerged as a key mechanism for tuning cellular morphology to light cues in cyanobacteria (Singh and Montgomery, 2014). Morphogene function in the regulation of cellular morphology generally is well known. The bacterial actin MreB is associated with rod-shaped bacteria, and is nearly always absent in spherical bacterial cells (reviewed by Cabeen and Jacobs-Wagner, 2007). MreB has functional homologs in cyanobacteria, both filamentous (Hu et al., 2007; González et al., 2010; Singh and Montgomery, 2014) and unicellular (Koksharova et al., 2007; Savage et al., 2010; Singh and Montgomery, unpublished data), which are associated with rodshaped cells. Mutation of $m r e B$ in cyanobacterial systems leads to a loss of shape regulation, thus resulting in the adoption of spherical cells in $\triangle m r e B$ mutants (Hu et al., 2007; Savage et al., 2010). In F. diplosiphon, in which rod-shaped cells are prevalent under GL, it appears that photoregulation of $m r e B$ expression corresponds to the induction of rod-shaped morphology (Singh and Montgomery, 2014).

A well-characterized regulator of $\mathrm{MreB}$ is the morphogene BolA (Aldea et al., 1989; Santos et al., 1999). Accumulation of BolA is associated with a spherical cell shape, and imparts this morphology in part through transcriptional downregulation of mreB (Aldea et al., 1988, 1989; Santos et al., 1999; Freire et al., 2009). In the first reported functional characterization of a cyanobacterial BolA protein, we recently showed that photoregulation of bolA expression in F. diplosiphon is correlated with RLdependent BolA accumulation that is associated with spherical morphology (Singh and Montgomery, 2014). Similar to E. coli BolA (Freire et al., 2009), BolA from F. diplosiphon binds the promotor of $m r e B$ to maintain low levels of $m r e B$ expression in RL (Singh and Montgomery, 2014). Lower levels of BolA are found in GL which are correlated with derepression of $m r e B$ expression, thereby resulting in the induction of a rod-shaped morphology in F. diplosiphon under these conditions (Singh and Montgomery, 2014).

\section{Additional Signals that Impact Cyanobacterial Morphology or Cellular Dimensions-ROS, Second Messengers, and Cell Cycle Factors}

Additional factors apart from morphogenes have been correlated with the regulation of cellular morphology in response to 
environmental cues in cyanobacteria. Some factors induced by environmental cues, including light, that impact cellular dimensions include reactive oxygen species (ROS), second messengers, and cell cycle or division cues.

\section{ROS as a Signal that Impacts Cellular Morphology of Cyanobacteria}

Reactive oxygen species are potent cues that can arise from photooxidative stress. When light absorption by the photosynthetic light-harvesting complexes exceeds the need for carbon fixation or the capacity of the photosynthetic electron transfer chains, absorbed light energy can be transferred to other targets resulting in production of ROS (reviewed by Busch and Montgomery, 2015). Generated ROS can then result in cellular photodamage and/or ROS molecules can serve as signals that impact cellular function or development (Busch and Montgomery, 2015). In cyanobacteria, light-generated ROS have been associated with the adoption of particular cellular morphologies. In F. diplosiphon, ROS levels are elevated in RL and this light-induced ROS accumulation is associated with spherical morphology (Singh and Montgomery, 2012; Singh et al., 2013). ROS levels are lower in GL and associated with rod-shaped $F$. diplosiphon cells (Singh and Montgomery, 2012; Singh et al., 2013). ROS specifically appear to be the signal impacting morphological adaptation as treatment of cells grown in RL with ROS-scavenging antioxidants reverses the ROS-associated impacts on cellular dimensions (Singh and Montgomery, 2012). In addition to the impact of ROS on cellular morphology, filament length is regulated by photoregulation of ROS. RL-associated elevated ROS accumulation is correlated with shorter filaments, presumably due to filament fragmentation (Singh and Montgomery, 2012). Notably, the RL vs. GL effects on ROS levels are regulated by the RL-responsive RcaE photoreceptor (Singh and Montgomery, 2012), a photoreceptor which regulates pigmentation and the photoregulation of morphology as described above (Kehoe and Grossman, 1996; Bordowitz and Montgomery, 2008). ROS levels are also elevated when light intensity is increased, which also is associated with the induction of a spherical cellular morphology (Walters et al., 2013). ROS have been associated with the regulation of cellular morphology in other systems, including non-photosynthetic organisms such as Aspergillus nidulans (Semighini and Harris, 2008) and specific phenotypes such as pollen germination and development, root elongation and cell expansion in plants (Foreman et al., 2003; Carol and Dolan, 2006; Li et al., 2007; Potocký et al., 2007; Müller et al., 2009; Speranza et al., 2012). One function of ROS in this regard is in cell wall loosening (Müller et al., 2009), potentially due to lipid peroxidation (He and Häder, 2002). This ROS-dependent impact could be linked to observed changes in cellular morphology.

The role of UV irradiation in spiral breakage or filament fragmentation in cyanobacteria has been associated with ROS formation (Ma and Gao, 2010; Rastogi et al., 2010, 2014). The accumulation of ROS has been implicated in the induction of lipid oxidation, which ultimately is hypothesized to lead to cellular damage and/or lysis (Ma and Gao, 2010; Rastogi et al., 2010). Thus, as in other systems, ROS molecules have the potential to serve as signaling molecules as proposed for the regulation of cellular morphology in F. diplosiphon or as molecules that cause potential damage such as cellular lysis (Busch and Montgomery, 2015). Ultimately, however, the morphology changes and/or filament fragmentation may be associated with improved fitness of strains in some cases. Early experiments with cyanobacteria demonstrated that targeted cell lysis at specialized cells along a filament can result in fragmentation or breakage of filaments into shorter filaments (Lamont, 1969; Bennett and Bogorad, 1973). Such filament fragmentation due to targeted cell lysis during the transition of $F$. diplosiphon cultures to RL was proposed to facilitate a reduction in the content of phycobiliproteins in the culture that are not optimal for growth in RL (Bennett and Bogorad, 1973). This morphological adaptation, thus, is associated with temporal tuning of the pigment content of the organism to the external light environment, which has been associated with optimizing photosynthetic efficiency (Campbell, 1996). Additionally, filament length regulation has been associated with fitness implications in a heterocyst-forming cyanobacterium, whereby the ability to restrict filament length under nitrogen-fixing conditions is associated with improved survival of Anabaena sp. strain PCC 7120 (Merino-Puerto et al., 2013).

\section{Second Messengers are Correlated with the Regulation of Cyanobacterial Cell Shape}

Second messengers serve as key signaling molecules used in cellular responses to external (or first messenger) cues. These molecules can be rapidly turned over in an energetically conservative manner to facilitate rapid changes in response to environmental fluctuations. Cyanobacteria contain a wide range of second messengers (Agostoni and Montgomery, 2014). Calcium is a ubiquitous second messenger utilized in response to a number of environmental cues that has been implicated in several cyanobacterial responses, including heterocyst development and homorgonia differentiation (reviewed by Agostoni and Montgomery, 2014). The second messengers guanosine pentaphosphate or tetraphosphate [(p)ppGpp] and cyclic AMP (cAMP) have been implicated specifically as mediators of cellular differentiation during cellular responses to nutrient availability (reviewed by Agostoni and Montgomery, 2014). Cyclic dimeric guanosine $3^{\prime}, 5^{\prime}$-monophosphate, i.e., c-di-GMP, presumably contributes to cell shape maintenance and cellular development in the filamentous cyanobacterium Anaebaena sp. PCC 7120 as deletion of putative c-di-GMP synthesis enzyme-encoding gene all2874 results in reduced heterocyst development and smaller vegetative cells under high light intensity (Neunuebel and Golden, 2008). Notably, cAMP (Ohmori et al., 1988, 2002; Ohmori and Okamoto, 2004; Okamoto et al., 2004; Terauchi and Ohmori, 2004) and cdi-GMP (Agostoni et al., 2013) levels are controlled by light in cyanobacteria. As many of these molecules have only recently begun to be the focus of studies in cyanobacteria (Agostoni and Montgomery, 2014), many additional second messengerregulated responses are expected to emerge.

\section{Coordination of Cell Cycle, Cell Division, and Central Carbon Metabolism with Cell Dimensions}

Cellular dimensions are largely heritable across a range of organisms, including prokaryotes and eukaryotes (Zaritsky, 1975; 
Fantes, 1977; Koch, 1996; Chien et al., 2012; Marshall et al., 2012; Turner et al., 2012; Lloyd, 2013; Campos et al., 2014). Cell size control is a core feature of the bacterial cell cycle under defined growth conditions (Campos et al., 2014). Bacterial cell size homeostasis appears to be regulated by reproducible and constant cell size extension (Campos et al., 2014; Soifer et al., 2014; TaheriAraghi et al., 2015). Coordination of cell growth or elongation and division during the cell cycle maintains and/or regulates cell size in bacteria, and can be impacted by nutrient availability or central metabolism (Weart et al., 2007; Siegal-Gaskins and Crosson, 2008; Chien et al., 2012; Yao et al., 2012; Hill et al., 2013; Robert et al., 2014).

Cell division and elongation in cyanobacteria have also been correlated (Koksharova and Wolk, 2002; Mazouni et al., 2004; Miyagishima et al., 2005; Marbouty et al., 2009; Gorelova et al., 2013). Although disruptions in cell division can result in elongated or filamentous cells, in some cases, the reversion of the impairment in cell division results in the restoration of the original cellular dimensions, providing evidence for the recognized strong regulation over cell size (Goclaw-Binder et al., 2012). Environmental cues such as nutrient availability can impact cell division and thereby impact cellular morphology in cyanobacteria (GoclawBinder et al., 2012), as described above for other bacterial systems.

An impact of central carbon metabolism on the cell cycle can affect cell size (reviewed by Vadia and Levin, 2015). While definitive experiments linking central carbon metabolism with cell size in cyanobacteria lag behind assessment in other systems, interesting phenomena have been reported. Cell division regulation that is associated with alterations in cell size has been shown to be impacted by sugar metabolism in Synechocystis (Osanai et al., 2013). This observed phenotype is driven by overexpression of a sigma factor gene, i.e., sigE, which impacts gene expression through interacting with the RNA polymerase (Osanai et al., 2013).

\section{Carbon-Concentrating Mechanism and Correlations with Cell Shape}

In cyanobacteria, carboxysomes are subcellular microcompartments centrally located in the cytoplasm of cells (Figure 1) and which are associated with the carbon-concentrating mechanism (CCM) and carbon fixation in cyanobacteria (Rae et al., 2013). In some studies, changes in carboxysome quantity and carboxysomal structural defects are apparent in elongated cell division mutants lacking ftn2 and ftn6 (Gorelova et al., 2013). Additionally, a disruption of apposite spatial distribution of carboxysomes in a mutant with cytoskeleton-associated defects in cellular morphology has been observed (Savage et al., 2010). Such observations suggest interactions between cellular shape and/or division

\section{References}

Adams, D. G., and Duggan, P. S. (2008). Cyanobacteria-bryophyte symbioses. J. Exp. Bot. 59, 1047-1058. doi: 10.1093/jxb/ern005

Agostoni, M., Koestler, B. J., Waters, C. M., Williams, B. L., and Montgomery, B. L. (2013). Occurrence of cyclic di-GMP-modulating output domains in cyanobacteria: an illuminating perspective. mBio 4, e00451-00413. doi: 10.1128/mBio. 00451-13 with the spatial organization of carboxysomes central to carbon metabolism.

The CCM can also include alterations to inorganic carbon (Ci) uptake or active transport. Low $\mathrm{Ci}$ levels result in a reduced trichome size in Arthrospira platensis (Ma and Gao, 2014). This reduction of trichome size is hypothesized to increase the surface area to cellular volume ratio. Such a response may serve in part to sustain photochemical efficiency and reduce potential damage under high light conditions, which are associated with an increased CCM (Beardall, 1991; Qiu and Liu, 2004).

\section{Conclusion}

Cyanobacteria and other cells can alter cellular dimensions and/or shape in response to environmental cues. In some cases this morphological adaptation is linked to the production of cells tuned to the external environment to increase fitness. In other cases, the fitness implications of the energy-requiring morphological adaptations are less clear or only beginning to emerge. For example, F. diplosiphon can alter cellular morphology in response to wavelength- or intensity-dependent cues that appear to be correlated with regulating cellular capacity for photosynthetic protein accumulation, which is linked to tuning the capacity of photosynthetic efficiency and associated carbon metabolism to external cues. Other cyanobacteria can alter trichome spiral length and/or filament morphology to reduce surface area exposed to potential damaging light, such as UV or high intensity light. Cells such as $A$. platensis and $C$. raciborskii can alter trichome size in response to cues such as light intensity and $\mathrm{Ci}$ availability, presumably to limit damage and alter surface to volume ratios that may alter resource acquisition to sustain photosynthesis. Additional analyses of the mechanisms by which morphological changes are regulated and the potential fitness costs and/or benefits may result in targets for engineering cyanobacterial strains for use in biotechnological applications, in addition to providing greater insight into the roles of these adaptations in natural contexts.

\section{Acknowledgments}

Work in the author's laboratory on the impacts of light on growth and development of cyanobacteria is supported by the National Science Foundation (grant no. MCB-1243983 to BM), whereas work on adapting cyanobacterial cultures for biotechnological applications is supported by the U.S. Department of Energy, Chemical Sciences, Geosciences and Biosciences Division, Office of Basic Energy Sciences, Office of Science (grant no. DE-FG0291ER20021 to BL). I would like to thank Dr. Bagmi Pattanaik for obtaining the transmission electron micrograph of Fremyella diplosiphon.

Agostoni, M., and Montgomery, B. (2014). Survival strategies in the aquatic and terrestrial world: the impact of second messengers on cyanobacterial processes. Life 4, 745-769. doi: 10.3390/life4040745

Aldea, M., Garrido, T., Hernandez-Chico, C., Vicente, M., and Kushner, S. (1989). Induction of a growth-phase-dependent promoter triggers transcription of bolA, an Escherichia coli morphogene. EMBO J. 8, 3923-3931.

Aldea, M., Hernández-Chico, C., De La Campa, A. G., Kushner, S. R., and Vicente, M. (1988). Identification, cloning, and expression of bolA, an 
ftsZ-dependent morphogene of Escherichia coli. J. Bacteriol. 170, 51695176.

Alvey, R. M., Karty, J. A., Roos, E., Reilly, J. P., and Kehoe, D. M. (2003). Lesions in phycoerythrin chromophore biosynthesis in Fremyella diplosiphon reveal coordinated light regulation of apoprotein and pigment biosynthetic enzyme gene expression. Plant Cell 15, 2448-2463. doi: 10.1105/tpc.015016

Beardall, J. (1991). Effects of photon flux density on the ' $\mathrm{CO}_{2}$-concentrating mechanism' of the cyanobacterium Anabaena variabilis. J. Plankton Res. 13, 133-141.

Bennett, A., and Bogorad, L. (1973). Complementary chromatic adaptation in a filamentous blue-green alga. J. Cell Biol. 58, 419-435.

Bittencourt-Oliveira, M., Buch, B., Hereman, T., Arruda-Neto, J., Moura, A., and Zocchi, S. (2012). Effects of light intensity and temperature on Cylindrospermopsis raciborskii (cyanobacteria) with straight and coiled trichomes: growth rate and morphology. Braz. J. Biol. 72, 343-351. doi: 10.1590/S151969842012000200016

Bordowitz, J. R., and Montgomery, B. L. (2008). Photoregulation of cellular morphology during complementary chromatic adaptation requires sensor-kinaseclass protein RcaE in Fremyella diplosiphon. J. Bacteriol. 190, 4069-4074. doi: $10.1128 / \mathrm{jb} .00018-08$

Bordowitz, J. R., Whitaker, M. J., and Montgomery, B. L. (2010). Independence and interdependence of the photoregulation of pigmentation and development in Fremyella diplosiphon. Commun. Integr. Biol. 3, 151-153. doi: 10.4161/cib.3.2.10367

Busch, A. W. U., and Montgomery, B. L. (2015). Interdependence of tetrapyrrole metabolism, the generation of oxidative stress and the mitigative oxidative stress response. Redox Biol. 4, 260-271. doi: 10.1016/j.redox.2015.01.010

Cabeen, M. T., and Jacobs-Wagner, C. (2005). Bacterial cell shape. Nat. Rev. Microbiol. 3, 601-610. doi: 10.1038/nrmicro1205

Cabeen, M. T., and Jacobs-Wagner, C. (2007). Skin and bones: the bacterial cytoskeleton, cell wall, and cell morphogenesis. J. Cell Biol. 179, 381-387. doi: $10.1083 /$ jcb.200708001

Campbell, D. (1996). Complementary chromatic adaptation alters photosynthetic strategies in the cyanobacterium Calothrix. Microbiology 142, 1255-1263.

Campos, M., Surovtsev, I. V., Kato, S., Paintdakhi, A., Beltran, B., Ebmeier, S. E., et al. (2014). A constant size extension drives bacterial cell size homeostasis. Cell 159, 1433-1446. doi: 10.1016/j.cell.2014.11.022

Carballido-López, R. (2006). Orchestrating bacterial cell morphogenesis. Mol. Microbiol. 60, 815-819. doi: 10.1111/j.1365-2958.2006.05161.x

Carol, R. J., and Dolan, L. (2006). The role of reactive oxygen species in cell growth: lessons from root hairs. J. Exp. Bot. 57, 1829-1834. doi: 10.1093/jxb/ erj201

Chien, A.-C., Hill, N. S., and Levin, P. A. (2012). Cell size control in bacteria. Curr. Biol. 22, R340-R349. doi: 10.1016/j.cub.2012.02.032

Cobley, J. G., Clark, A. C., Weerasurya, S., Queseda, F. A., Xiao, J. Y., Bandrapali, N., et al. (2002). CpeR is an activator required for expression of the phycoerythrin operon (cpeBA) in the cyanobacterium Fremyella diplosiphon and is encoded in the phycoerythrin linker-polypeptide operon (cpeCDESTR). Mol. Microbiol. 44, 1517-1531. doi: 10.1046/j.1365-2958.2002.02966.x

Daniel, J. W., and Rusch, H. P. (1962). Method for inducing sporulation of pure cultures of the myxocmycete Physarum polycephalum. J. Bacteriol. 83, 234-240.

Desnos, T., Orbović, V., Bellini, C., Kronenberger, J., Caboche, M., Traas, J., et al. (1996). Procuste1 mutants identify two distinct genetic pathways controlling hypocotyl cell elongation, respectively in dark- and light-grown Arabidopsis seedlings. Development 122, 683-693.

Dyachok, J., Zhu, L., Liao, F., He, J., Huq, E., and Blancaflor, E. B. (2011). SCAR mediates light-induced root elongation in Arabidopsis through photoreceptors and proteasomes. Plant Cell 23, 3610-3626. doi: 10.1105/tpc.111.088823

Fantes, P. A. (1977). Control of cell size and cycle time in Schizosaccharomyces pombe. J. Cell Sci. 24, 51-67.

Flores, E., and Herrero, A. (2010). Compartmentalized function through cell differentiation in filamentous cyanobacteria. Nat. Rev. Microbiol. 8, 39-50. doi: 10.1038/nrmicro2242

Foreman, J., Demidchik, V., Bothwell, J. H. F., Mylona, P., Miedema, H., Torres, M. A., et al. (2003). Reactive oxygen species produced by NADPH oxidase regulate plant cell growth. Nature 422, 442-446. doi: 10.1038/nature01485

Freire, P., Moreira, R. N., and Arraiano, C. M. (2009). BolA inhibits cell elongation and regulates MreB expression levels. J. Mol. Biol. 385, 1345-1351. doi: 10.1016/j.jmb.2008.12.026
Gao, K., Yu, H., and Brown, M. T. (2007). Solar PAR and UV radiation affects the physiology and morphology of the cyanobacterium Anabaena sp. PCC 7120. J. Photochem. Photobiol. B 89, 117-124. doi: 10.1016/j.jphotobiol.2007.09. 006

Gendreau, E., Traas, J., Desnos, T., Grandjean, O., Caboche, M., and Höfte, H. (1997). Cellular basis of hypocotyl growth in Arabidopsis thaliana. Plant Physiol. 114, 295-305.

Goclaw-Binder, H., Sendersky, E., Shimoni, E., Kiss, V., Reich, Z., Perelman, A., et al. (2012). Nutrient-associated elongation and asymmetric division of the cyanobacterium Synechococcus PCC 7942. Environ. Microbiol. 14, 680-690. doi: $10.1111 / j .1462-2920.2011 .02620 . x$

González, A., Teresa Bes, M., Barja, F., Peleato, M. L., and Fillat, M. F. (2010). Overexpression of FurA in Anabaena sp. PCC 7120 reveals new targets for this regulator involved in photosynthesis, iron uptake and cellular morphology. Plant Cell Physiol. 51, 1900-1914. doi: 10.1093/pcp/pcq148

Gorelova, O. A., Baulina, O. I., Rasmussen, U., and Koksharova, O. A. (2013). The pleiotropic effects of $\mathrm{ftn} 2$ and $\mathrm{ftn} 6$ mutations in cyanobacterium Synechococcus sp. PCC 7942. Protoplasma 250, 931-942. doi: 10.1007/s00709-012-0479-2

Gutu, A., and Kehoe, D. M. (2012). Emerging perspectives on the mechanisms, regulation, and distribution of light color acclimation in cyanobacteria. Mol. Plant 5, 1-13. doi: $10.1093 / \mathrm{mp} / \mathrm{ssr} 054$

He, Y. Y., and Häder, D. P. (2002). Involvement of reactive oxygen species in the UV-B damage to the cyanobacterium Anabaena sp. J. Photochem. Photobiol. $B$ 66, 73-80. doi: 10.1016/S1011-1344(01)00278-0

Hill, N. S., Buske, P. J., Shi, Y., and Levin, P. A. (2013). A moonlighting enzyme links Escherichia coli cell size with central metabolism. PLoS Genet. 9:e1003663. doi: 10.1371/journal.pgen.1003663

Hu, B., Yang, G., Zhao, W., Zhang, Y., and Zhao, J. (2007). MreB is important for cell shape but not for chromosome segregation of the filamentous cyanobacterium Anabaena sp. PCC 7120. Mol. Microbiol. 63, 1640-1652. doi: 10.1111/j.13652958.2007.05618.x

Kadota, A., and Wada, M. (1992). Reorganization of the cortical cytoskeleton in tip-growing fern protonemal cells during phytochrome-mediated phototropism and blue light-induced apical swelling. Protoplasma 166, 35-41. doi: $10.1007 / \mathrm{bf01320140}$

Kaplan-Levy, R., Hadas, O., Summers, M., Rücker, J., and Sukenik, A. (2010). "Akinetes: dormant cells of cyanobacteria," in Dormancy and Resistance in Harsh Environments, eds E. Lubzens, J. Cerda, and M. Clark (Berlin: Springer), 5-27.

Kehoe, D. M., and Grossman, A. R. (1996). Similarity of a chromatic adaptation sensor to phytochrome and ethylene receptors. Science 273, 1409-1412.

Koch, A. L. (1996). What size should a bacterium be? A question of scale. Annu. Rev. Microbiol. 50, 317-348. doi: 10.1146/annurev.micro.50.1.317

Koksharova, O. A., Klint, J., and Rasmussen, U. (2007). Comparative proteomics of cell division mutants and wild-type of Synechococcus sp. strain PCC 7942. Microbiology 153, 2505-2517. doi: 10.1099/mic.0.2007/007039-0

Koksharova, O. A., and Wolk, C. P. (2002). A novel gene that bears a DnaJ motif influences cyanobacterial cell division. J. Bacteriol. 184, 5524-5528. doi: 10.1128/JB.184.19.5524-5528.2002

Kumar, K., Mella-Herrera, R. A., and Golden, J. W. (2010). Cyanobacterial heterocysts. Cold Spring Harb. Perspect. Biol. 2, a000315. doi: 10.1101/cshperspect.a000315

Lamont, H. (1969). Sacrificial cell death and trichome breakage in an oscillatoriacean blue-green alga: the role of murein. Arch. Mikrobiol. 69, 237-259. doi: 10.1007/bf00408976

Li, H. B., Qin, Y. M., Pang, Y., Song, W. Q., Mei, W. Q., and Zhu, Y. X. (2007). A cotton ascorbate peroxidase is involved in hydrogen peroxide homeostasis during fibre cell development. New Phytol. 175, 462-471. doi: 10.1111/j.14698137.2007.02120.x

Lindeboom, J. J., Nakamura, M., Hibbel, A., Shundyak, K., Gutierrez, R., Ketelaar, T., et al. (2013). A mechanism for reorientation of cortical microtubule arrays driven by microtubule severing. Science 342,1245533 . doi: 10.1126/science. 1245533

Lloyd, A. C. (2013). The regulation of cell size. Cell 154, 1194-1205. doi: 10.1016/j.cell.2013.08.053

Ma, Z., and Gao, K. (2009). Photoregulation of morphological structure and its physiological relevance in the cyanobacterium Arthrospira (Spirulina) platensis. Planta 230, 329-337. doi: 10.1007/s00425-009-0947-x

Ma, Z., and Gao, K. (2010). Spiral breakage and photoinhibition of Arthrospira platensis (Cyanophyta) caused by accumulation of reactive oxygen species 
under solar radiation. Environ. Exp. Bot. 68, 208-213. doi: 10.1016/j.envexpbot. 2009.11.010

$\mathrm{Ma}, \mathrm{Z}$., and Gao, K. (2014). Carbon limitation enhances $\mathrm{CO}_{2}$ concentrating mechanism but reduces trichome size in Arthrospira platensis (cyanobacterium). J. Appl. Phycol. 26, 1465-1472. doi: 10.1007/s10811-013-0181-6

Marbouty, M., Saguez, C., Cassier-Chauvat, C., and Chauvat, F. (2009). ZipN, an FtsA-like orchestrator of divisome assembly in the model cyanobacterium Synechocystis PCC 6803. Mol. Microbiol. 74, 409-420. doi: 10.1111/j.13652958.2009.06873.x

Margolin, W. (2009). Sculpting the bacterial cell. Curr. Biol. 19, R812-R822. doi: 10.1016/j.cub.2009.06.033

Marshall, W., Young, K., Swaffer, M., Wood, E., Nurse, P., Kimura, A., et al. (2012). What determines cell size? BMC Biol. 10:101. doi: 10.1186/1741-7007-10-101

Marwan, W. (2001). "Photomovement and photomorphogenesis in Physarum polycephalum: targeting of cytoskeleton and gene expression by light," in Comprehensive Series in Photosciences, eds D. P. Häder and A. M. Breure (Amsterdam: Elsevier), 561-587.

Mathur, J. (2004). Cell shape development in plants. Trends Plant Sci. 9, 583-590. doi: 10.1016/j.tplants.2004.10.006

Mazouni, K., Domain, F., Cassier-Chauvat, C., and Chauvat, F. (2004). Molecular analysis of the key cytokinetic components of cyanobacteria: FtsZ, ZipN and MinCDE. Mol. Microbiol. 52, 1145-1158. doi: 10.1111/j.1365-2958.2004. 04042.x

Meeks, J. C., and Elhai, J. (2002). Regulation of cellular differentiation in filamentous cyanobacteria in free-living and plant-associated symbiotic growth states. Mol. Microbiol. Biol. Rev. 66, 94-121. doi: 10.1128/mmbr.66.1.94-121.2002

Merino-Puerto, V., Herrero, A., and Flores, E. (2013). Cluster of genes that encode positive and negative elements influencing filament length in a heterocystforming cyanobacterium. J. Bacteriol. 195, 3957-3966. doi: 10.1128/JB.00181-13

Miyagishima, S. Y., Wolk, C. P., and Osteryoung, K. W. (2005). Identification of cyanobacterial cell division genes by comparative and mutational analyses. Mol. Microbiol. 56, 126-143. doi: 10.1111/j.1365-2958.2005.04548.x

Montgomery, B. L. (2008). Shedding new light on the regulation of complementary chromatic adaptation. Cent. Eur. J. Biol. 3, 351-358. doi: 10.2478/s11535-0080039-0

Müller, K., Linkies, A., Vreeburg, R. A., Fry, S. C., Krieger-Liszkay, A., and LeubnerMetzger, G. (2009). In vivo cell wall loosening by hydroxyl radicals during cress seed germination and elongation growth. Plant Physiol. 150, 1855-1865. doi: 10.1104/pp.109.139204

Neunuebel, M. R., and Golden, J. W. (2008). The Anabaena sp. strain PCC 7120 gene all2874 encodes a diguanylate cyclase and is required for normal heterocyst development under high-light growth conditions. J. Bacteriol. 190, 6829-6836. doi: 10.1128/jb.00701-08

Nishihama, R., Ishizaki, K., Hosaka, M., Matsuda, Y., Kubota, A., and Kohchi, T. (2015). Phytochrome-mediated regulation of cell division and growth during regeneration and sporeling development in the liverwort Marchantia polymorpha. J. Plant Res. 1-15. doi: 10.1007/s10265-015-0724-9

Ohmori, M., Ohmori, K., and Hasunuma, K. (1988). Rapid change in cyclic 3', $5^{\prime}$-AMP concentration triggered by a light-off or light-on signal in Anabaena cylindrica. Arch. Microbiol. 150, 203-204.

Ohmori, M., and Okamoto, S. (2004). Photoresponsive cAMP signal transduction in cyanobacteria. Photochem. Photobiol. Sci. 3, 503-511. doi: 10.1039/b401623h

Ohmori, M., Terauchi, K., Okamoto, S., and Watanabe, M. (2002). Regulation of cAMP-mediated photosignaling by a phytochrome in the cyanobacterium Anabaena cylindrica. Photochem. Photobiol. 75, 675-679. doi: 10.1562/00318655(2002)075<0675:ROCMPB $>2.0$. CO;2

Okamoto, S., Kasahara, M., Kamiya, A., Nakahira, Y., and Ohmori, M. (2004). A phytochrome-like protein AphC triggers the cAMP signaling induced by far-red light in the cyanobacterium Anabaena sp. strain PCC7120. Photochem. Photobiol. 80, 429-433. doi: 10.1562/0031-8655(2004)080<0429:APPATT>2.0.CO;2

Osanai, T., Kuwahara, A., Iijima, H., Toyooka, K., Sato, M., Tanaka, K., et al. (2013). Pleiotropic effect of sigE over-expression on cell morphology, photosynthesis and hydrogen production in Synechocystis sp. PCC 6803. Plant J. 76, 456-465. doi: $10.1111 /$ tpj. 12310

Osborn, M. J., and Rothfield, L. (2007). Cell shape determination in Escherichia coli. Curr. Opin. Microbiol. 10, 606-610. doi: 10.1016/j.mib.2007.09.004

Pattanaik, B., and Montgomery, B. L. (2010). A novel role for a TonB-family protein and photoregulation of iron acclimation in Fremyella diplosiphon. Plant Signal. Behav. 5, 851-853. doi: 10.4161/psb.5.7.11827
Pattanaik, B., Whitaker, M. J., and Montgomery, B. L. (2011a). Convergence and divergence of the photoregulation of pigmentation and cellular morphology in Fremyella diplosiphon. Plant Signal. Behav. 6, 2038-2041. doi: 10.4161/psb.6.12.18239

Pattanaik, B., Whitaker, M. J., and Montgomery, B. L. (2011b). Regulation of phycoerythrin synthesis and cellular morphology in Fremyella diplosiphon green mutants. Biochem. Biophys. Res. Commun. 413, 182-188. doi: 10.1016/j.bbrc.2011.08.051

Pattanaik, B., Whitaker, M. J., and Montgomery, B. L. (2012). Light quantity affects the regulation of cell shape in Fremyella diplosiphon. Front. Microbiol. 3:170. doi: 10.3389/fmicb.2012.00170

Poetsch, B., Schreckenbach, T., and Werenskiold, A. K. (1989). Photomorphogenesis in Physarum polycephalum: temporal expression pattern of actin, $\alpha$ and $\beta$-tubulin. Eur. J. Biochem. 179, 141-146. doi: 10.1111/j.1432-1033.1989. tb14531.x

Postius, C., Neuschaefer-Rube, O., Haid, V., and Böger, P. (2001). N2-fixation and complementary chromatic adaptation in non-heterocystous cyanobacteria from Lake Constance. FEMS Microbiol. Ecol. 37, 117-125. doi: 10.1111/j.15746941.2001.tb00859.x

Potocký, M., Jones, M. A., Bezvoda, R., Smirnoff, N., and Žárský, V. (2007). Reactive oxygen species produced by NADPH oxidase are involved in pollen tube growth. New Phytol. 174, 742-751. doi: 10.1111/j.1469-8137.2007. 02042.x

Putzer, H., Verfuerth, C., Claviez, M., and Schreckenbach, T. (1984). Photomorphogenesis in Physarum: induction of tubulins and sporulation-specific proteins and of their mRNAs. Proc. Natl. Acad. Sci. U.S.A. 81, 7117-7121.

Qiu, B., and Liu, J. (2004). Utilization of inorganic carbon in the edible cyanobacterium Ge-Xian-Mi (Nostoc) and its role in alleviating photo-inhibition. Plant Cell Environ. 27, 1447-1458. doi: 10.1111/j.1365-3040.2004.01248.x

Rae, B. D., Long, B. M., Whitehead, L. F., Forster, B., Badger, M. R., and Price, G. D. (2013). Cyanobacterial carboxysomes: microcompartments that facilitate $\mathrm{CO}_{2}$ fixation. J. Mol. Microbiol. Biotechnol. 23, 300-307. doi: 10.1159/000351342

Rastogi, R. P., Incharoensakdi, A., and Madamwar, D. (2014). Responses of a rice-field cyanobacterium Anabaena siamensis TISTR-8012 upon exposure to PAR and UV radiation. J. Plant Physiol. 171, 1545-1553. doi: 10.1016/j.jplph.2014.07.011

Rastogi, R. P., Singh, S. P., Häder, D.-P., and Sinha, R. P. (2010). Detection of reactive oxygen species (ROS) by the oxidant-sensing probe $2^{\prime}, 7^{\prime}$. dichlorodihydrofluorescein diacetate in the cyanobacterium Anabaena variabilis PCC 7937. Biochem. Biophys. Res. Commun. 397, 603-607. doi: 10.1016/j.bbrc.2010.06.006

Rausenberger, J., Hussong, A., Kircher, S., Kirchenbauer, D., Timmer, J., Nagy, F., et al. (2010). An integrative model for phytochrome B mediated photomorphogenesis: from protein dynamics to physiology. PLoS ONE 5:e10721. doi: 10.1371/journal.pone.0010721

Reed, J. W., Nagatani, A., Elich, T. D., Fagan, M., and Chory, J. (1994). Phytochrome A and phytochrome B have overlapping but distinct functions in Arabidopsis development. Plant Physiol. 104, 1139-1149.

Rippka, R., Deruelles, J., Waterbury, J. B., Herdman, M., and Stanier, R. Y. (1979). Generic assignments, strain histories and properties of pure cultures of cyanobacteria. Microbiology 111, 1-61. doi: 10.1099/00221287-111-1-1

Robert, L., Hoffmann, M., Krell, N., Aymerich, S., Robert, J., and Doumic, M. (2014). Division in Escherichia coli is triggered by a size-sensing rather than a timing mechanism. BMC Biol. 12:17. doi: 10.1186/1741-7007-12-17

Sachetto-Martins, G., Franco, L. O., and De Oliveira, D. E. (2000). Plant glycine-rich proteins: a family or just proteins with a common motif? Biochim. Biophys. Acta 1492, 1-14. doi: 10.1016/S0167-4781(00)00064-6

Santos, J. M., Freire, P., Vicente, M., and Arraiano, C. M. (1999). The stationaryphase morphogene bolA from Escherichia coli is induced by stress during early stages of growth. Mol. Microbiol. 32, 789-798.

Savage, D. F., Afonso, B., Chen, A. H., and Silver, P. A. (2010). Spatially ordered dynamics of the bacterial carbon fixation machinery. Science 327, 1258-1261. doi: $10.1126 /$ science. 1186090

Seib, L. O., and Kehoe, D. M. (2002). A turquoise mutant genetically separates expression of genes encoding phycoerythrin and its associated linker peptides. J. Bacteriol. 184, 962-970. doi: 10.1128/jb.184.4.962-970.2002

Semighini, C. P., and Harris, S. D. (2008). Regulation of apical dominance in Aspergillus nidulans hyphae by reactive oxygen species. Genetics 179, 1919-1932. doi: 10.1534 /genetics. 108.089318 
Siegal-Gaskins, D., and Crosson, S. (2008). Tightly regulated and heritable division control in single bacterial cells. Biophys. J. 95, 2063-2072. doi: 10.1529/biophysj.108.128785

Singh, S. P., Miller, H. L., and Montgomery, B. L. (2013). Temporal dynamics of changes in reactive oxygen species (ROS) levels and cellular morphology are coordinated during complementary chromatic acclimation in Fremyella diplosiphon. Photosyn. Res. 1-10. doi: 10.1007/s11120-013-9938-7 [Epub ahead of print].

Singh, S. P., and Montgomery, B. L. (2011). Determining cell shape: adaptive regulation of cyanobacterial cellular differentiation and morphology. Trends Microbiol. 19, 278-285. doi: 10.1016/j.tim.2011.03.001

Singh, S. P., and Montgomery, B. L. (2012). Reactive oxygen species are involved in the morphology-determining mechanism of Fremyella diplosiphon cells during complementary chromatic adaptation. Microbiology 158, 2235-2245. doi: 10.1099/mic.0.060475-0

Singh, S. P., and Montgomery, B. L. (2014). Morphogenes bolA and mreB mediate the photoregulation of cellular morphology during complementary chromatic acclimation in Fremyella diplosiphon. Mol. Microbiol. 93, 167-182. doi: 10.1111/mmi.12649

Smith, L. G. (2003). Cytoskeletal control of plant cell shape: getting the fine points. Curr. Opin. Plant Biol. 6, 63-73. doi: 10.1016/S1369-5266(02)00012-2

Soifer, I., Robert, L., Barkai, N., and Amir, A. (2014). Single-cell analysis of growth in budding yeast and bacteria reveals a common size regulation strategy. arXiv preprint. arXiv: 1410.4771

Speranza, A., Crinelli, R., Scoccianti, V., and Geitmann, A. (2012). Reactive oxygen species are involved in pollen tube initiation in kiwifruit. Plant Biol. (Stuttg.) 14, 64-76. doi: 10.1111/j.1438-8677.2011.00479.x

Stewart, G. C. (2005). Taking shape: control of bacterial cell wall biosynthesis. Mol. Microbiol. 57, 1177-1181. doi: 10.1111/j.1365-2958.2005.04760.x

Taheri-Araghi, S., Bradde, S., Sauls, J. T., Hill, N. S., Levin, P. A., Paulsson, J., et al. (2015). Cell-size control and homeostasis in bacteria. Curr. Biol. 25, 385-391. doi: 10.1016/j.cub.2014.12.009

Tandeau de Marsac, N. (1991). "Chromatic adaptation by cyanobacteria," in Cell Culture and Somatic Cell Genetics of Plants, eds L. Bogorad and I. K. Vasil (New York: Academic Press), 417-446.

Terauchi, K., and Ohmori, M. (2004). Blue light stimulates cyanobacterial motility via a cAMP signal transduction system. Mol. Microbiol. 52, 303-309. doi: 10.1111/j.1365-2958.2003.03980.x

Terenna, C. R., Makushok, T., Velve-Casquillas, G., Baigl, D., Chen, Y., Bornens, M., et al. (2008). Physical mechanisms redirecting cell polarity and cell shape in fission yeast. Curr. Biol. 18, 1748-1753. doi: 10.1016/j.cub.2008.09.047

Turner, J. J., Ewald, J. C., and Skotheim, J. M. (2012). Cell size control in yeast. Curr. Biol. 22, R350-R359. doi: 10.1016/j.cub.2012.02.041

Ueki, N., and Nishii, I. (2009). Controlled enlargement of the glycoprotein vesicle surrounding a Volvox embryo requires the InvB nucleotide-sugar transporter and is required for normal morphogenesis. Plant Cell 21, 1166-1181. doi: $10.1105 /$ tpc. 109.066159
Vadia, S., and Levin, P. A. (2015). Growth rate and cell size: a re-examination of the growth law. Curr. Opin. Microbiol. 24, 96-103. doi: 10.1016/j.mib.2015.01.011

Walters, K. J., Whitaker, M. J., Singh, S. P., and Montgomery, B. L. (2013). Light intensity and reactive oxygen species are centrally involved in photoregulatory responses during complementary chromatic adaptation in Fremyella diplosiphon. Commun. Integr. Biol. 6, e25005. doi: 10.4161/cib.25005

Weart, R. B., Lee, A. H., Chien, A. C., Haeusser, D. P., Hill, N. S., and Levin, P. A. (2007). A metabolic sensor governing cell size in bacteria. Cell 130, 335-347. doi: 10.1016/j.cell.2007.05.043

Whitaker, M. J., Bordowitz, J. R., and Montgomery, B. L. (2009). CpcF-dependent regulation of pigmentation and development in Fremyella diplosiphon. Biochem. Biophys. Res. Commun. 389, 602-606. doi: 10.1016/j.bbrc.2009.09.030

Whitaker, M. J., Pattanaik, B., and Montgomery, B. L. (2011). Characterization of green mutants in Fremyella diplosiphon provides insight into the impact of phycoerythrin deficiency and linker function on complementary chromatic adaptation. Biochem. Biophys. Res. Commun. 404, 52-56. doi: 10.1016/j.bbrc.2010.11.056

Wong, F. C. Y., and Meeks, J. C. (2002). Establishment of a functional symbiosis between the cyanobacterium Nostoc punctiforme and the bryophyte Anthoceros punctatus requires genes involved in nitrogen control and initiation of heterocyst differentiation. Microbiology 148, 315-323.

Wu, H., Gao, K., Villafane, V. E., Watanabe, T., and Helbling, E. W. (2005). Effects of solar UV radiation on morphology and photosynthesis of filamentous cyanobacterium Arthrospira platensis. Appl. Environ. Microbiol. 71, 5004-5013. doi: 10.1128/aem.71.9.5004-5013.2005

Yao, Z., Davis, R. M., Kishony, R., Kahne, D., and Ruiz, N. (2012). Regulation of cell size in response to nutrient availability by fatty acid biosynthesis in Escherichia coli. Proc. Natl. Acad. Sci. U.S.A. 109, E2561-E2568. doi 10.1073/pnas.1209742109

Young, K. D. (2006). The selective value of bacterial shape. Microbiol. Mol. Biol. Rev. 70, 660-703. doi: 10.1128/MMBR.00001-06

Young, K. D. (2007). Bacterial morphology: why have different shapes? Curr. Opin. Microbiol. 10, 596-600. doi: 10.1016/j.mib.2007.09.009

Zaritsky, A. (1975). On dimensional determination of rod-shaped bacteria. J. Theor. Biol. 54, 243-248.

Conflict of Interest Statement: The author declares that the research was conducted in the absence of any commercial or financial relationships that could be construed as a potential conflict of interest.

Copyright (c) 2015 Montgomery. This is an open-access article distributed under the terms of the Creative Commons Attribution License (CC BY). The use, distribution or reproduction in other forums is permitted, provided the original author(s) or licensor are credited and that the original publication in this journal is cited, in accordance with accepted academic practice. No use, distribution or reproduction is permitted which does not comply with these terms. 